University of Zurich

Department of Economics

Working Paper Series

ISSN 1664-7041 (print)

ISSN 1664-705X (online)

Working Paper No. 98

\title{
Use and Abuse of Authority: A Behavioral Foundation of the Employment Relation
}

Björn Bartling, Ernst Fehr and Klaus M. Schmidt

November 2012 


\title{
Use and Abuse of Authority
}

\section{A Behavioral Foundation of the Employment Relation*}

\author{
Björn Bartling ${ }^{\text {a) }}$, Ernst Fehr ${ }^{\text {b) }}$ and Klaus M. Schmidt ${ }^{\text {c) }}$
}

November 14, 2012

\begin{abstract}
Employment contracts give a principal the authority to decide flexibly which task his agent should execute. However, there is a tradeoff, first pointed out by Simon (1951), between flexibility and employer moral hazard. An employment contract allows the principal to adjust the task quickly to the realization of the state of the world, but he may also abuse this flexibility to exploit the agent. We capture this tradeoff in an experimental design and show that principals exhibit a strong preference for the employment contract. However, selfish principals exploit agents in one-shot interactions, inducing them to resist entering into employment contracts. This resistance to employment contracts vanishes if fairness preferences in combination with reputation opportunities keep principals from abusing their power, leading to the widespread, endogenous formation of efficient long-run employment relations. Our results inform the theory of the firm by showing how behavioral forces shape an important transaction cost of integration - the abuse of authority - and by providing an empirical basis for assessing differences between the Marxian and the Coasian view of the firm, as well as Alchian and Demsetz's (1972) critique of the Coasian approach.
\end{abstract}

Keywords: theory of the firm, transaction cost economics, authority, power abuse, employment relation, fairness, reputation

JEL: C91, D23, D86, M5

\footnotetext{
*) Financial support from the Deutsche Forschungsgemeinschaft through SFB-TR 15, the Excellence Initiative of the German government though MELESSA, the Swiss National Science Foundation (project number 101312103898/1), and the Research Priority Program on the "Foundations of Human Social Behavior" at the University of Zurich is gratefully acknowledged.

a) Björn Bartling, Department of Economics, University of Zurich, Blümlisalpstrasse 10, CH-8006 Zurich, Switzerland, email: bjoern.bartling@econ.uzh.ch

b) Ernst Fehr, Department of Economics and Laboratory for Social and Neural Systems Research, University of Zurich, Blümlisalpstrasse 10, CH-8006 Zurich, Switzerland, email: ernst.fehr@econ.uzh.ch

c) Klaus M. Schmidt, Department of Economics, University of Munich, Ludwigstraße 28, D-80539 Munich, Germany, email: klaus.schmidt@LMU.de
} 


\section{Introduction}

Under which conditions is a transaction more efficiently conducted in a firm than in a market? Coase (1937) was the first to raise this question, and it has since become the defining theme of the theory of the firm. An early theoretical contribution to this literature is Simon (1951), who compared transactions carried out in markets via sales contracts and transactions governed by employment contracts in firms. Simon argued that there is a tradeoff between flexibility and employer moral hazard. A sales contract is a contract for the execution of a specific task, while an employment contract gives authority or power to the employer to decide (within the limits of the contract) which task the employee has to provide. On the one hand, the employment contract is advantageous because the employer can quickly adjust the task to be executed to new information such as short-term changes in demand. On the other hand, the employment contract gives rise to an employer moral hazard problem because the employer has the power to force the employee to choose an inefficient action that is profitable for the employer but very costly for the employee. A sales contract solves the employer moral hazard problem by determining the task to be executed in advance, but it is less flexible and might turn out to be inefficient ex-post.

In this paper, we report on a set of experiments designed to better understand how and under which conditions employment contracts are viable in the presence of the employer moral hazard problem. In our experiments, a principal decides whether to offer an employment contract or a sales contract to an agent. A sales contract determines the task the agent is to execute before an ex-ante uncertain state of the world is realized. The fixed task assignment might turn out to be inefficient ex-post, but it has the advantage that the agent knows the exact cost of the task execution when he decides whether or not to accept the contract offer. This is important to the agent, as different tasks have different costs. An employment contract is more flexible and gives the principal the authority to assign the task after the state of the world is realized. But since the agent has to decide whether to accept the contract before he knows which task he will have to execute, the employment contract gives the principal the opportunity to exploit the agent once the contract is accepted. The principal has the power to demand that the agent execute a task that is most profitable for the former, even though it is very expensive for the agent and therefore inefficient. This experimental setup captures an important aspect of the legal situation in many countries in which the 
employer has the legal right to tell the employees what to do within the limits defined by the respective labor law. ${ }^{1}$

We conducted two main treatments with a finite number of periods, one with fixed and one with random identification numbers (IDs). Our treatment with random IDs ("RANDOM”) only allows for one-shot interactions. Our treatment with fixed IDs ("FIXED”) allows the subjects to endogenously form long-term relations, as they can identify each other across periods. For example, an agent is able to recognize that a given employment contract offer comes from a principal who did not abuse power in a previous interaction governed by an employment contract. $^{2}$

If all subjects are rational and self-interested, employment contracts are not viable in treatment RANDOM because purely self-interested principals would always exploit the agents. Rational agents will anticipate this and only accept employment contracts if the wages are high enough to cover the effort cost of the exploitative task. However, because this task is inefficient, it does not pay for principals to offer an employment contract at these wages. Furthermore, the principal will also not offer an employment contract in treatment FIXED because the parties can only interact for a known, finite number of periods. Models of social preferences (e.g., Rabin 1993, Fehr and Schmidt 1999) predict that some principals are fairminded and thus refrain from exploiting their agents - even in treatment RANDOM. The existence of fair-minded principals implies that even purely self-interested principals in treatment FIXED might initially refrain from abusing their power in order to appear as fair principals and thus establish a potentially profitable long-term employment relationship. These strategic principals will only start exploiting their agents towards the end of the game.

We find that power abuse in employment contracts is indeed relatively frequent in treatment RANDOM; the principals demand their most profitable yet inefficient task in roughly half of the cases. However, the employers treat their workers fairly in the other half of the cases; they demand the efficient task from their employees and share the efficiency

\footnotetext{
${ }^{1}$ In Germany, for example, the employer's authority to give directives ("Weisungsrecht”) is stipulated in §106 of the German Industrial Code ("Gewerbeordnung"): "The employer can determine the content, place, and time of job performance more precisely in equitable discretion unless the conditions of employment are determined by the labor contract, provisions of a company agreement, an applicable collective labor agreement, or legal provisions.” The original German version is provided online by German Federal Ministry of Justice: www.gesetze-im-internet.de/gewo/. In the U.S., negotiated management rights clauses spell out an employer's autonomy in managing a firm or organization, such as assigning work to employees.

${ }^{2}$ We call the imposition of the most profitable yet inefficient task in the employment contract an "abuse of power" or "exploitative" because the principals could announce which task they intend to assign in each state of the world, but these announcements were not binding. The principals announced that they would not impose the most profitable yet very costly task on the agent in 98.2 percent of all employment contract offers. Thus, apart from imposing very high costs on the agents, the imposition of this task also represents the break of an announced intention in almost all cases.
} 
benefits of the employment contract with them. Both selfish and fair principals exhibit a strong preference for the employment contract. Selfish principals prefer it because it allows them to make higher profits at the cost of their agent, while fair principals prefer it because they benefit from being able to implement the efficient task. As a consequence, the frequency of employment contracts is initially very high because the agents trusted their principals' promises. However, due to the relatively high rate of power abuse, the workers not only experienced a high degree of uncertainty in the employment contracts but also earned on average less than in sales contracts. Therefore, the workers showed increasing resistance to employment contracts. This resistance eventually led to a majority of sales contracts; the share of employment contracts settled at about 40 percent.

Why did employment contracts not completely vanish in treatment RANDOM? The reason is that the share of fair principals was still sufficiently high to keep them viable. We prove this claim with a control treatment using random IDs in which the employment contracts are designed in such a way that the principal is forced to impose the most profitable but inefficient task on the agent in 80 percent of the cases. We call this treatment "UNFAIR" because the agent knows that he will be treated unfairly most of the time if he accepts an employment contract. The share of employment contracts indeed converges to very low levels very quickly in this treatment.

These facts contrast sharply with the data pattern observed in treatment FIXED. Here, more than 80 percent of all concluded contracts are employment contracts, significantly more than in treatment RANDOM. As in treatment RANDOM, the principals show a strong preference for employment contracts in treatment FIXED from the beginning, but far fewer principals abuse their power. Instead, they implement the efficient task and share the returns with the agent. Therefore, both principal and agent prefer the employment contract, i.e., the sharp conflict of interest with regard to the type of contract that we observed in treatment RANDOM vanishes.

Why do the principals abuse their power much less often in treatment FIXED? The agents' threat of terminating the employment relationship disciplines the principals, which in turn causes a substantial loss in a principal's future profit. It is, therefore, in the principal's interest to establish a non-abusive relation with his agent, which turns the employment contract into a long-run relationship that is mutually beneficial for both parties. In contrast, sales contracts remain short run encounters between the parties.

What are the implications of our experimental findings for the efficiency of sales and employment contracts? We identify three types of transaction costs in our experiments: First, 
some profitable trade opportunities are lost because some contract offers are rejected. Second, the surplus in sales contracts is reduced because they are inflexible. Third, some principals abuse their power under employment contracts and force the agent to execute an inefficient task. There is no significant difference in total transaction costs between sales and employment contracts in treatment RANDOM. Total transaction costs are significantly lower under employment contracts than under sales contracts in treatment FIXED, however. Viable authority relationships under employment contracts thus arise endogenously as the dominant mode of governance only when both principals' fairness preferences and reputation building mechanisms are present.

Our paper makes a contribution to the transaction cost economics (TCE) view of the firm. Starting with the seminal papers by Monteverde and Teece (1982) and Masten (1984), a large body of empirical work documents a positive correlation between the size of transaction costs in markets, e.g. due to contract rigidity or the hold-up problem, and the likelihood of vertical integration. Gibbons (2010), however, points out that "essentially all TCE empirical papers on vertical integration have asked whether proxies for unprogrammed adaptation and lock-in make integration more likely, with very few asking instead whether factors that increase the cost of integration make non-integration more likely" (p. 277). Our paper thus differs from most of the existing empirical literature in TCE, as we focus on how variations in the transaction cost of integration - the principals' abuse of power under employment contracts - affect the likelihood of integration (i.e. employment contracts). We examine, in particular, the behavioral forces - fairness preferences and reputation formation - that determine the transaction cost of integration, and we can explicitly show that there is a negative and monotonic relationship between this transaction cost of integration and the frequency of vertical integration.

Moreover, our experimental approach also addresses a shortcoming in the existing empirical tests of theories of the firm that Gibbons summarizes by stating that "it remains the case that empirical work in TCE (and in organizational economics more generally) could stand to pay more attention to identification strategies" (Gibbons 2010, p. 279). In other words, the existing field evidence mainly provides correlational evidence. Our experimental design, in contrast, provides exogenous variation in, first, the principals' ability to build a reputation (treatment FIXED vs. treatment RANDOM) and, second, their ability to act in a fair way (treatment RANDOM vs. treatment UNFAIR). Our data show that these treatment variations affect the costs of integration (the frequency of the principals' abuse of power), while our treatments, by design, do not affect the costs of non-integration (the inability to 
adapt to new information under sales contracts). Our experimental design thus provides clean, causal evidence on the effect of the transaction costs of integration on the choice of the governance mode.

To the best of our knowledge, the only other experimental paper that directly addresses the origins of authority/hierarchy in the context of the theory of the firm is Grosse, Putterman, and Rockenbach (2011). They test Alchian and Demsetz's (1972) claim that successful team production requires concentrated control in the hands of a specialized monitor who receives the residual rewards. They find that their subjects usually prefer peer monitoring, but if monitoring by team members becomes more costly than monitoring by the specialist, peer monitoring often fails and a trend towards specialist monitoring emerges.

Although we do not set up a team production environment, the results of our paper also have a bearing on the debate between Alchian and Demsetz (1972) and the Coasian view of the firm (Coase 1937, Simon 1951). In his 1937 paper, Coase famously described the internal structure of a firm as a system in which power and subordination replace the market. Alchian and Demsetz (1972) dispute this characterization of the firm by claiming that there is no difference between the employer's power to manage and assign workers to tasks and a "little consumer's" power to manage and assign his grocer to tasks. Our paper suggests, however, that very different forces govern the relationship between the "little consumer" and the grocer and that this relationship is of a very different nature than that between an employer and a worker. A sales contract regulates the relationship between the consumer and the grocer, i.e. the consumer has no legal right to direct the grocer's activities and the grocer faces no risk of abusive task assignment. In contrast, if an agent enters into an employment contract, then the employer could assign tasks that exploit the agent. To prevent an abuse of power, the two parties have to enter into a repeated relationship that leaves a rent to the employer that he would lose if he exploited the agent and the agent terminated the relationship. No such rent is needed to discipline the consumer who enters a sales contract with his grocer.

Our paper is also related to the theory of contracts as reference points by Hart and Moore (2008), which also explains the existence of employment contracts (among several other insights). In their approach, the psychology of reference points and reference dependent fairness concerns play important roles. Thus, both Hart and Moore's account and our approach take psychological forces into account that standard contract theory has neglected. ${ }^{3}$

\footnotetext{
${ }^{3}$ Fehr, Hart and Zehnder (2011) provide supportive experimental evidence for the Hart and Moore approach.
} 
In addition, both accounts provide an efficiency rationale for the existence of employment contracts. However, while labor contracts are "naturally" turned into long-run employment relations in our setting if the employer moral hazard problem is solved, Hart and Moore do not provide an explanation for why the labor contract typically takes the form of a long-run employment relation because their model is static.

Finally, because we study the principals' incentives to use authority in (in)efficient ways, our paper provides a framework in which one can assess the Marxian view of the firm (Marglin 1974, 1975). In particular, we are able to identify the conditions under which employers are likely to abuse their authority. Moreover, to the extent to which reputational forces alone are insufficient for solving the employers' moral hazard problem, labor unions and labor legislation can play an efficiency enhancing role by constraining the employers' ability to assign the workers inefficient tasks.

The remainder of the paper is organized as follows. Section 2 explains our experimental design. Section 3 discusses several important features this design. Section 4 derives predictions based on the pure self-interest theory and models of social preferences. Section 5 presents our experimental results. Section 6 discusses the implications of our approach for the theory of the firm. Here we discuss Alchian and Demsetz's critique of the Coasian approach in more detail. We also compare the Coasian view of authority to the Marxian view of power, and we relate our paper to recent contributions on high-performance work systems. Section 7 summarizes and concludes the paper.

\section{Experimental Design and Procedures}

Our experimental design captures the trade-off in Simon's (1951) theory of the employment relationship between rigid sales contracts in markets and flexible employment contracts in firms. An employer can respond to new information and assign tasks efficiently, but he can also abuse his power to the employee's disadvantage.

In our experiments, a principal can conclude a contract with an agent for the execution of a task. If a contract is concluded, the agent executes a task and receives a fixed wage in return. Task execution generates revenue for the principal but imposes a personal cost on the agent. The principal's profit is revenue minus wage, and the agent's income is wage less the cost of task execution. There are three possible tasks, the execution of which incur different costs for the agent. Tasks 1,2 , and 3 result in costs of 0 , 40, and 130, respectively (see Table 
1). ${ }^{4}$ There are also two different states of the world that affect the principal's revenue from task execution. In state 1, task 1 generates revenue of 160, while task 2 generates only 80 . In state 2, task 2 generates revenue of 200, while task 1 generates only 30. Irrespective of the state of the world, task 3 always generates the highest revenue: 190 in state 1 and 230 in state 2. Since task 3 is very costly for the agent, however, it is never efficient. Instead, task 1 is efficient in state 1 , and task 2 is efficient in state 2. In both cases, a maximum surplus of 160 can be generated. ${ }^{5}$ Table 1 gives an overview of revenue, cost, surplus, principal's profit, and agent's income for the three different tasks in the two possible states of the world.

TABLE 1 - Tasks, States, and Payoffs.

\begin{tabular}{clccc}
\hline & & Task 1 & Task 2 & Task 3 \\
\hline \hline \multirow{5}{*}{ State 1} & Revenue & 160 & 80 & 190 \\
& Cost & 0 & 40 & 130 \\
& Surplus & 160 & 40 & 60 \\
& Principal's profit & $160-$ wage & $80-$ wage & $190-$ wage \\
& Agent's income & wage & wage -40 & wage -130 \\
\hline \multirow{5}{*}{ State 2} & Revenue & 30 & 200 & 230 \\
& Cost & 0 & 40 & 130 \\
& Surplus & 30 & 160 & 100 \\
& Principal's profit & $30-$ wage & $200-$ wage & $230-$ wage \\
& Agent's income & wage & wage -40 & wage -130 \\
\hline
\end{tabular}

Neither principal nor agent initially knows the state of the world. It is realized with equal probability and becomes publicly known only after a contract between principal and agent has been concluded. The state of the world is not contractible.

We consider two types of contracts. A principal can either offer a sales contract that specifies both a wage and a fixed task to be executed. Or he can offer an employment contract that only specifies the wage and gives the principal authority to specify the task after the realization of the state of the world. An employment contract offer includes an announcement from the principal of the task he intends to demand in the different states of the world, but the announcement is not binding. Once an agent accepts an employment contract, the principal has the power to demand any of the three tasks.

\footnotetext{
${ }^{4} 15$ experimental points were exchanged for CHF 1 (approximately EUR 0.66 at the time of the experiments) at the end of the experiment. In the following, all numbers refer to experimental points.

${ }^{5}$ As is explained below, agents have an outside option of 30, which reduces the surplus accordingly.
} 
Since the state of the world is not contractible, a sales contract cannot be state contingent. Given the later realization of the state of the world, the agreed upon task may thus be inefficient. In contrast, an employment contract has the advantage that the principal can assign the task after observing the state of the world. He can always opt to assign the efficient task, i.e., task 1 in state 1 and task 2 in state 2, which generates the maximum surplus of 160 in both states of the world. However, the employment contract also enables the principal to abuse his power and choose the inefficient task 3, which is always most profitable for him but very costly for the agent. The employment contract thus gives rise to an employer moral hazard problem. The employer moral hazard problem is absent in a sales contract, because a sales contract fixes the task the agent must carry out. From an ex ante perspective, the most efficient sales contract asks for task 2, generating an expected surplus of 100, while sales contracts requiring task 1 or 3 yield expected surpluses of 95 or 80, respectively. Figure 1 summarizes the timing of the principal-agent relationship.

\begin{tabular}{|c|c|c|c|}
\hline $\mathrm{t}=1$ & $t=2$ & $t=3$ & $\mathrm{t}=4$ \\
\hline $\begin{array}{c}\text { Principals } \\
\text { make their } \\
\text { contract offers }\end{array}$ & $\begin{array}{l}\text { Agents decide } \\
\text { whether or not to } \\
\text { accept their } \\
\text { contract offers }\end{array}$ & $\begin{array}{l}\text { Principals and agents learn the } \\
\text { state of the world. Under an } \\
\text { employment contract, the } \\
\text { principal determines the task. }\end{array}$ & $\begin{array}{c}\text { Tasks are } \\
\text { executed and } \\
\text { payoffs are } \\
\text { made. }\end{array}$ \\
\hline
\end{tabular}

FIGURE 1.-Sequence of Events.

We implemented groups of 8 principals and 8 agents in each session of the experiment. Each principal can contract with one agent at most, and each agent can accept one contract offer at most. Each subject receives a unique identification number (ID). In the contracting stage, each principal has to make two contract offers. First, he makes a private contract offer addressed to a single, specific agent identified by his ID that only this agent can accept. Second, he makes a public contract offer not addressed to a specific agent that any agent may accept. After all principals have made two contract offers, the private contracting stage begins in which the private offers are shown to the respective agents. An agent can receive none, one, or several private offers. If he receives one or several offers, he can accept at most one of them. He can also reject his private offer(s). After all agents have decided about their private offers, those agents without a private contract offer enter the public contracting stage. The remaining agents only see the public contract offers of those principals whose private offers were rejected. The agents choose among the public contract offers in a 
randomly determined sequential order. The first agent sees all public contract offers and can accept at most one of them. The second agent receives the remaining offers, and so on. This matching procedure ensures that each agent receives at least one private or public contract offer. Principals and agents who conclude a contract then learn about the realization of the state of the world. Under an employment contract, the principal determines the task that his agent has to perform. Finally, payoffs are made. If a principal does not conclude a contract, his profit is zero. If an agent does not conclude a contract, he receives an outside option of 30.

Subjects played the above game for 15 periods. We implemented two main treatments and one control treatment. In treatment RANDOM, all players' IDs are randomly assigned at the beginning of each period. It is thus impossible for principals and agents to identify a subject with whom they may have interacted in a previous period. In contrast, the principals' and agents' IDs are fixed for all 15 periods of the game in treatment FIXED. Apart from the assignment of the IDs, the two treatments are identical. Treatment RANDOM restricts principals and agents to one-shot interactions. Treatment FIXED enables principals and agents to form long-term relations. A principal can address his private contract offer to a specific agent, e.g., to the agent with whom he contracted in an earlier period. An agent can also identify the principal making a contract offer. If an agent accepted, for example, an employment contract in a previous period and the principal did not abuse his power, then the agent can recognize this principal in the current period. A principal can thus build a reputation for not exploiting his agent in treatment FIXED, which is not possible in treatment RANDOM. The comparison between treatments FIXED and RANDOM allows us to analyze whether the principals' opportunity to develop a reputation enhances the endogenous emergence of employment contracts. In addition, this treatment enables us to study the behavioral strategies that solve the principals' moral hazard problem and shape the contractual relationship between the parties.

We conducted three sessions of treatment FIXED and three sessions of treatment RANDOM. We implemented two matching groups of 16 subjects in each session, yielding six independent matching groups for each treatment.

We also conducted a single session of control treatment UNFAIR, with two matching groups of 16 subjects. Treatment UNFAIR is identical to treatment RANDOM, except that there is a probability of 80 percent that task 3 will be exogenously imposed on the agent under an employment contract. Consequently, there is only a 20 percent probability that the principal will be free to choose the task. This rule was common knowledge among all 
subjects. An agent who accepted an employment contract thus knew that he would have to perform task 3 in at least 80 percent of the cases. Treatment UNFAIR manipulates the agents' beliefs about the prevalence of task 3 assignments, which allows a better understanding of why employment contracts are offered and accepted in treatment RANDOM.

Upon arrival in the lab, half of the subjects were randomly and anonymously assigned the role of a principal, the other half the role of an agent. The experiment was framed as a labor market interaction. We avoided value laden terms such as authority, power, fairness, or exploitation. We referred to an employment contract as a "flexible contract" and to a sales contract as a "fixed contract."

Sessions lasted about $2 \frac{1}{2}$ hours and took place at the Department of Economics at the University of Zurich between April and December 2009. Subjects were students from the University of Zurich and the Swiss Federal Institute of Technology in Zurich studying various majors except economics and psychology. The experiments were computerized using the software z-Tree (Fischbacher 2007). On average, subjects earned about CHF 63.70 (about EUR 42.30 at the time of the experiments), which included a show-up fee of CHF 10 (EUR $6.70)$.

\section{Discussion of Design Features}

We discuss several critical features of our experimental design in this section. We deliberately kept our design as simple as possible, while retaining our ability to capture the essence of the problem of power abuse in employment contracts. One of these simplifications becomes visible in the fact that we allow for "only" two states of the world and three tasks. In addition, we make the simplifying assumption that the agent's costs are the same in all states of the world. Obviously, there are many more states of the world in practice and the task space is highly multi-dimensional, implying that there are a very large number of tasks available for almost any job. ${ }^{6}$

We restrict our design to a small number of states and tasks to reduce the complexity of the experiment for the subjects and to minimize the possibility that subjects' misperceptions of the situation confound the observed data patterns and behavioral regularities. This simplification has the consequence that there are - in principle - contractual

\footnotetext{
${ }^{6}$ Even for the case in which the principal needs a well-defined single output from the agent, the following questions arise: when, where, at which speed, at which quality and quantity needs the output be available. All these dimensions have implications for the agent's effort and can be varied continuously. They should, therefore, be considered as different tasks.
} 
solutions to the employer's moral hazard problem available in our experiment that, however, cannot work in a slightly more complicated environment.

One might, for example, ask why it is not possible to rule out task 3 in employment contracts in our set up, which would immediately solve the power abuse problem and render employment contracts efficient even in treatment RANDOM. Recall that the state of the world is not verifiable in our experiment, while the tasks are verifiable and can be determined in an enforceable contract. However, by simply adding a third state in which task 3 is much more efficient than the other two tasks implies that the trading parties do not want to rule out task 3. More generally, the power abuse problem exists when some tasks are efficient in some states of the world but abusive in others.

Because task assignment is verifiable, one may also ask why the principal could not offer task dependent wages in the employment contract. Task-dependent wages can solve the power abuse problem in our set up because the principal can commit not to impose task 3 by contractually agreeing to a wage $w_{3}$ for task 3 such that $w_{3}-w_{1} \geq 130$ and $w_{3}-w_{2} \geq 90$. It would never be in the principal's interest to impose task 3 for these wages because this task is only profitable for the principal if he does not have to internalize the agent's effort cost. However, it is easy to see that task-dependent wages can work in practice only if there are a small number of tasks. If the task space becomes large - as is typically the case - taskdependent wages are likely to be associated with prohibitively high transaction costs. In addition, even if there is only a small number of tasks, task-dependent wages need not solve the power abuse problem if the agent's costs are state-dependent.

To see this in more detail, consider the following example: Task 1 leads to revenue of 200 in state 1 and to revenue of 220 in state 2 . The agent's costs are 20 and 100 in states 1 and 2, respectively. Task 2 leads to revenue of 220 in state 1 and to revenue of 200 in state 2. The agent's costs are 100 and 20 in states 1 and 2, respectively. In this example, task 1 is efficient in state 1 and task 2 is efficient in state 2. Suppose now that the two wages, $w_{1}$ and $w_{2}$, obey the condition $200-w_{1}>220-w_{2}$ (or $w_{2}-w_{1}>20$ ), implying that the principal prefers task 1 in state 1 . In this case, the principal also prefers task 1 in state 2 because 220 $w_{1}>200-w_{2}$ also holds. Thus, the principal has an incentive to impose high costs on the agent in state 2 even though this is inefficient. Suppose now that the reverse inequality holds, i.e. $200-w_{2}>220-w_{1}$ (or $w_{1}-w_{2}>20$ ) such that the principal prefers the efficient task 2 in state 2. Yet this means that the principal also prefers task 2 in state 1 even though this 
imposes high costs on the agent and is inefficient. Task-dependent wages provide, therefore, no solution to the power abuse problem when the costs are state-dependent.

Another important topic concerns the possibility of renegotiation. We do not allow for renegotiation of the contract after the state of the world has been revealed in our experiment. If the parties could costlessly and efficiently renegotiate the initial contract, the difference between an authority contract and a sales contract would disappear. Both contracts would be renegotiated to the efficient task, and the first best efficient allocation would always be implemented. However, renegotiations are neither costless nor do they always reach an expost efficient outcome. Renegotiations can be infeasible because decisions often have to be made quickly. Furthermore, they can be costly if asymmetries of information exist between the two parties that render the bargaining outcome inefficient. More recently Hart and Moore (2008) and Herweg and Schmidt (2012) argue that contracts serve as reference points that affect the parties' ex-post behavior, giving rise to different (inefficient) renegotiation outcomes after an authority and a sales contract. ${ }^{7}$ In this paper, we want to show that there is an alternative mechanism to renegotiation, namely relational contracts, that get the parties close to the first best without invoking costly renegotiation. To show this as cleanly as possible, we abstract away from the possibility of renegotiation.

A related issue concerns the possibility of the agent walking away from the contract if the principal requires him to do task 3. If the agent's wage is smaller than 160, his utility from completing task 3 is smaller than his outside option utility. Nevertheless, we assume that the agent has to carry out task 3 for the following reasons. First, once he started working for the principal, the agent's outside option is gone and he has to incur search and switching costs to find a new job. Second, the principal could threaten to sue the agent for unilateral breach of contract. Even if it is not clear that the principal would win the law suit, the threat of a law suit may be sufficient to induce the worker to finish his job. Finally, not completing his job could result in a reputational loss for the agent.

Finally, one may ask why we did not take the agents' effort choices explicitly into account in our experimental design. While it is true that principals have the right to assign tasks to the workers under an employment contract, it is also true that the execution of the tasks requires the agents' effort. In case of imperfect monitoring and enforcement technologies, it would be possible for agents to retaliate to the assignment of abusive tasks by

\footnotetext{
${ }^{7}$ Fehr, Hart and Zehnder (2011, 2012) and Bartling and Schmidt (2012) provide evidence that contracts serve as reference points. Fehr, Hart and Zehnder (2012) and Bartling and Schmidt (2012) show that the type of contract influences the renegotiation process and that renegotiations can be inefficient.
} 
reducing their effort. However, because we wanted to focus exclusively on the principals' moral hazard problem, we avoided the complications of explicit effort choices. Our experimental design is therefore best interpreted as a situation in which the principals have implemented a strong monitoring and enforcement technology such that effort reductions relative to the principals' desired effort level are very costly for the worker.

\section{Behavioral Predictions}

The central question the experiments in this paper address is whether the widespread emergence of employment contracts occurs if principals have the opportunity to acquire a reputation of not abusing their agents, and if so, which behavioral strategies support this solution to the principals' moral hazard problem. Different assumptions about the principals' preferences suggest different answers to this question.

\subsection{Self-interest model}

The standard neoclassical approach assumes that all people are fully rational and only interested in maximizing their own material payoffs. In this case, the (second best) optimal contract is straightforward. ${ }^{8}$

The interaction between the principal and the agent is one-shot in treatments RANDOM and UNFAIR. If the agent accepts an employment contract, the principal will always require task 3 because this yields the highest revenue in either state of the world. Agents anticipate this and only accept an employment contract if the wage compensates them for the effort cost of 130 and the opportunity cost of 30. The same is true for the sales contract on task 3. Both contracts thus yield the principal an expected profit of $0.5 \cdot 230+0.5 \cdot 190-(130+30)=50$. The effort cost for task 1 is 0 , so the wage in a sales contract on task 1 only has to compensate for the opportunity cost, and the principal's expected profit is $0.5 \cdot 160+0.5 \cdot 30-30=65$. The wage in a sales contract for task 2 has to compensate for effort costs of 40 and the opportunity cost, so the principal's expected profit

\footnotetext{
${ }^{8}$ In the following we assume that all parties are risk neutral and maximize their expected monetary income. Note that principals in the experiments could first make a private offer to one agent and a public offer to all agents that became relevant only if the private offer was rejected. To simplify the exposition, we ignore the twostage structure of the bargaining game in the theoretical analysis and assume that the principal makes a take-itor-leave-it offer either to an anonymous agent (in treatment RANDOM) or to a known agent (in treatment FIXED). However, it would not be difficult to extend the equilibrium strategies in such a way that they form an equilibrium with the same equilibrium outcome in the two-stage bargaining game too.
} 
is $0.5 \cdot 80+0.5 \cdot 200-(40+30)=70$. In equilibrium, the principal will thus offer a sales contract on task 2 with a wage of $w=70$, which the agent accepts.

The same prediction prevails in treatment FIXED. The principal will require task 3 under an employment contract independent of the history of past play in the last period. Agents anticipate this and accept an employment contract only if the wage is at least $w=$ 160. Given this high wage, the principal will offer a sales contract for task 2 with a wage of $w=70$ in the last period in any subgame perfect equilibrium. By backward induction, this outcome is also the unique prediction for all previous periods.

Thus, the self-interest model gives rise to the following hypothesis:

Hypothesis 1 [Self-interest Model]: The employment contract is not viable in any of the three treatments because principals will always require task 3 if it is accepted. Agents anticipate this and accept employment contracts only if $w \geq 160$. Because of this high wage, the employment contract is not profit maximizing and principals prefer offering sales contracts for task 2.

\subsection{Social preferences}

The predictions of the self-interest model are based on the assumption that a principal will always require the agent to do the task that is most profitable for the principal, independent of how costly this is for the agent. Models of social preferences (e.g., Rabin 1993, Fehr and Schmidt 1999, Bolton and Ockenfels 2000, Dufwenberg and Kirchsteiger 2004, Falk and Fischbacher, 2006, Battigalli and Dufwenberg, 2007) assume instead that some people are "fair-minded”. Fair-minded principals may refrain from exploiting the agent, because they reciprocate to the agent's "kind" action of accepting the contract, because they are averse to inequality, or because they feel guilt for exploiting agents.

If there are both selfish and fair-minded types of principals, all three treatments turn into signaling games with potentially many perfect Bayesian equilibria. It is always an equilibrium in all treatments for both types of principals to offer a sales contract on task 2 in every period. Such an equilibrium is sustained by the out-of-equilibrium belief that the principal is selfish with probability one if he offers an employment contract. There may also be equilibria in treatment RANDOM where both types of principals offer an employment contract. Suppose that an agent believes that a share $x \in(0,1)$ of principals is selfish and requires task 3 under an employment contract, while a share of $1-x$ is fair-minded and 
chooses the efficient task 1 or 2 . In this case, accepting an employment contract is profitable for the agent if

$$
w-x \cdot 130-(1-x) \cdot[0.5 \cdot 40+0.5 \cdot 0] \geq 30 \Leftrightarrow x \leq \frac{w-50}{110}
$$

i.e. given the wage $w$, agents must be sufficiently optimistic that they face a fair principal. ${ }^{9}$ For example, if $w=105$, agents only accept the employment contract if they believe they face a selfish principal with at most a probability of 50 percent, if $w=116$, this probability may not be larger than 60 percent, and so on.

While there may be equilibria with employment contracts in treatment RANDOM if agents are sufficiently optimistic about their principal's type, this is impossible in treatment UNFAIR. Task 3 is imposed exogenously with 80 percent probability in this case. Thus, even if the principal always chooses the efficient task in the remaining 20 percent of all cases, social surplus is only

$$
0.8 \cdot[0.5 \cdot(230-130)+0.5 \cdot(190-130)]+0.2 \cdot[0.5 \cdot(200-40)+0.5 \cdot(160-0)]=96
$$

while the expected surplus of a sales contract on task 2 is 100 . This implies that a sales contract dominates an employment contract in task 2 for a fair-minded principal, because a sales contract for task 2 exists for any given wage of an employment contract that makes both the principal and the agent better off. Hence, a fair-minded principal will never choose an employment contract in any equilibrium of treatment UNFAIR. If there was an equilibrium in which the employment contract is offered with positive probability, agents must believe that a selfish principal offers it, so they would require at least a wage such that

$$
w-130 \geq 30 \Leftrightarrow w \geq 160
$$

which leaves at most an expected profit of $210-160=50$ for the selfish principal. But this implies that the employment contract is also dominated for the selfish principal, because he could offer a sales contract on task 2 that generates a higher surplus and makes both him and the agent better off. Hence, the sales contract on task 2 must be offered in any equilibrium of treatment UNFAIR.

In treatment FIXED, it need not be the case (as in RANDOM and UNFAIR) that a selfish principal always requires task 3 if an employment contract has been accepted. Here

\footnotetext{
${ }^{9}$ This condition is also sufficient if agents accept any contract that yields an expected payoff that is at least as high as their outside option. However, if some agents accept a contract only if they get at least some share of the surplus in addition to their outside option (e.g., because they are inequality averse), the condition becomes more stringent. We have no specific beliefs about the underlying fairness preferences and look for joint predictions that all models of social preferences share.
} 
there are reputation equilibria along the lines of Kreps et al. (1982) in which both types of principal form a long-term relationship with their agent. They make a private offer for an employment contract and choose the efficient tasks 1 and 2 in all but the last few periods of the game. The agent accepts the private offer if his principal did not exploit him in any of the previous periods. Otherwise, he rejects the private offer and accepts the best public offer from the other principals. In the last few periods, the equilibrium unravels and selfish principals require task 3 with positive probability.

The theoretical discussion is summarized in the following hypothesis:

Hypothesis 2 [Social Preferences]: If some principals are motivated by social preferences and do not exploit the agent under an employment contract, we get:

a) In treatment RANDOM, employment contracts may be offered and accepted if agents are sufficiently optimistic about facing a fair principal. However, all selfish principals will exploit their agents and require task 3 under an employment contract.

b) All contract offers are sales contracts for task 2 in treatment UNFAIR.

c) Employment contracts may be offered and accepted in treatment FIXED, even if agents are less optimistic about facing a fair principal. Fair and selfish principals may form long-term relationships with their agents, offer employment contracts and choose the efficient tasks 1 and 2 only (except possibly for the last few periods of the game). Thus, there will be more employment contracts and less unfair behavior than in treatment RANDOM.

\section{Results}

\subsection{Authority and the Abuse of Power in One-shot Relations}

In treatment RANDOM, the self-interest model predicts that principals will always abuse their power in an employment contract and assign the agent the inefficient task 3, while models of social preferences predict that some principals will behave fairly and choose the efficient tasks 1 or 2 . The following result summarizes actual behavior under employment contracts if there are only one-shot interactions. 


\section{Result 1 (Power abuse under one-shot employment contracts): The principals in treatment RANDOM implement the inefficient but profit maximizing task 3 in the employment contract in roughly half of the cases (51 percent), but they behave fairly and use their power to implement the efficient tasks 1 or 2 in the other half of the cases.}

Result 1 shows that there is a significant share of principals who behave fairly and efficiently even in one-shot interaction. ${ }^{10}$ The result thus rejects Hypothesis 1 (pure self-interest), while it is consistent with Hypothesis 2 (social preferences).

This raises the question whether the share of fair principals is sufficiently high so that agents are better off under employment contracts compared to sales contracts. Employment contracts clearly have advantages for principals. Selfish principals can use them to exploit their agents, while fair principals can share a larger surplus. For agents, however, employment contracts entail a substantial risk of exploitation.

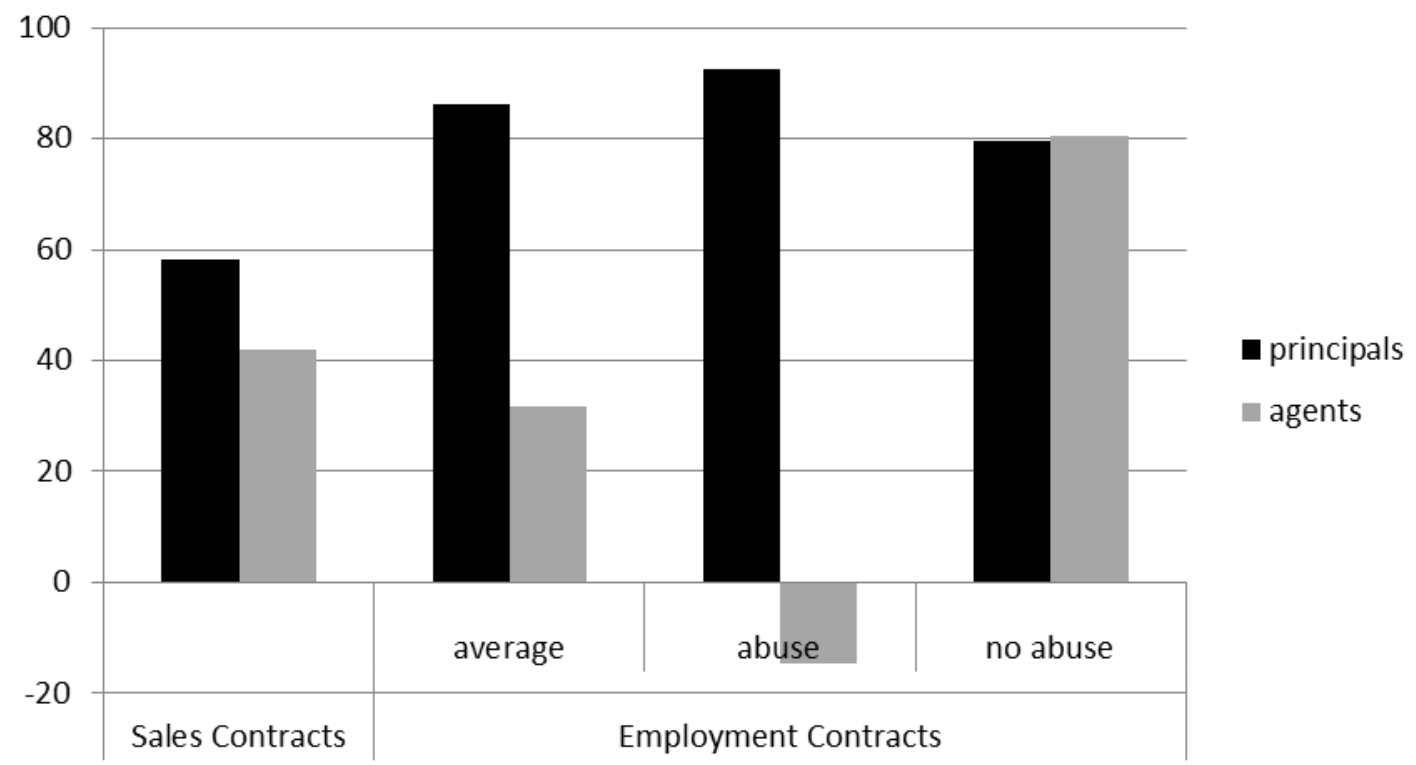

FIGURE 2.-Principals’ profits and agents' incomes with concluded contracts in treatment RANDOM.

Figure 2 shows that principals realize higher profits under concluded employment contracts (86.3) than under concluded sales contracts (58.2). Agents, however, realize higher incomes under sales contracts (41.9) than under employment contracts (31.6). On average, higher

\footnotetext{
${ }^{10}$ In treatment RANDOM, when a principal did not impose task 3, he always chose the efficient task.
} 
wages are paid under employment contracts (109.8) than under sales contracts (64.9), but the difference only partially compensates the agents for the risk of exploitation. In fact, agents with an employment contract make on average little more than their outside option of 30, so accepting these contracts was just profitable. Looking at matching group averages, the income differences between contract types are highly significant for principals but not for agents (rank-sum tests on matching group averages, $\mathrm{p}=0.004$ and $\mathrm{p}=0.109$, respectively). ${ }^{11}$

Figure 2 also shows that even the principals who do not abuse their power make significantly higher profits under employment contracts (79.6) compared to the sales contracts (rank-sum test on matching group averages, $\mathrm{p}=0.025$ ). These principals offer wages of about 105 and share the surplus equally with their agents: both principals and agents receive on average almost exactly half of the maximum surplus of 160 . The principals who abuse their power make significantly higher profits (92.6) than the fair principals (rank-sum test on matching group averages, $\mathrm{p}=0.010$ ), but their agents make substantial losses on average (-14.8). This is summarized in our next result.

\section{Result 2 (Conflict of interest over contract types): In treatment RANDOM, principals realize significantly higher profits under employment contracts than under sales contracts, even if they do not abuse their power. Agents realize lower incomes under employment contracts than under sales contracts. While the difference in average incomes is not significant for agents, employment contracts entail the risk of exploitation and incurring substantial losses.}

Given this strong conflict of interest, it is not obvious which type of contract will prevail because although the principals have the power to offer employment contracts, the agents may not accept them. Figure 3 shows that most principals start out offering only employment contracts and most of them are initially accepted; therefore, the share of employment contracts is very high at the beginning. However, the agents experience over time that the principals frequently abuse their power to assign tasks, so that the agents start rejecting many of the offered employment contracts. ${ }^{12}$ This is why sales contracts eventually dominate. If the principals offer a sales contract then they demand the relatively more efficient task 2 in the large majority of the cases. ${ }^{13}$ Nevertheless, Figure 3 shows that a stable share of 40 percent

\footnotetext{
${ }^{11}$ All p-values shown in the text are two-sided.

${ }^{12}$ Contract rejections are discussed in more detail in Section 5.3.

${ }^{13}$ Sales contracts for tasks 1 and 3 account for less than 15 percent of all contracts in treatment RANDOM.
} 
employment contracts among all concluded contracts persists even in the last periods of the experiment. We summarize this in our next result.

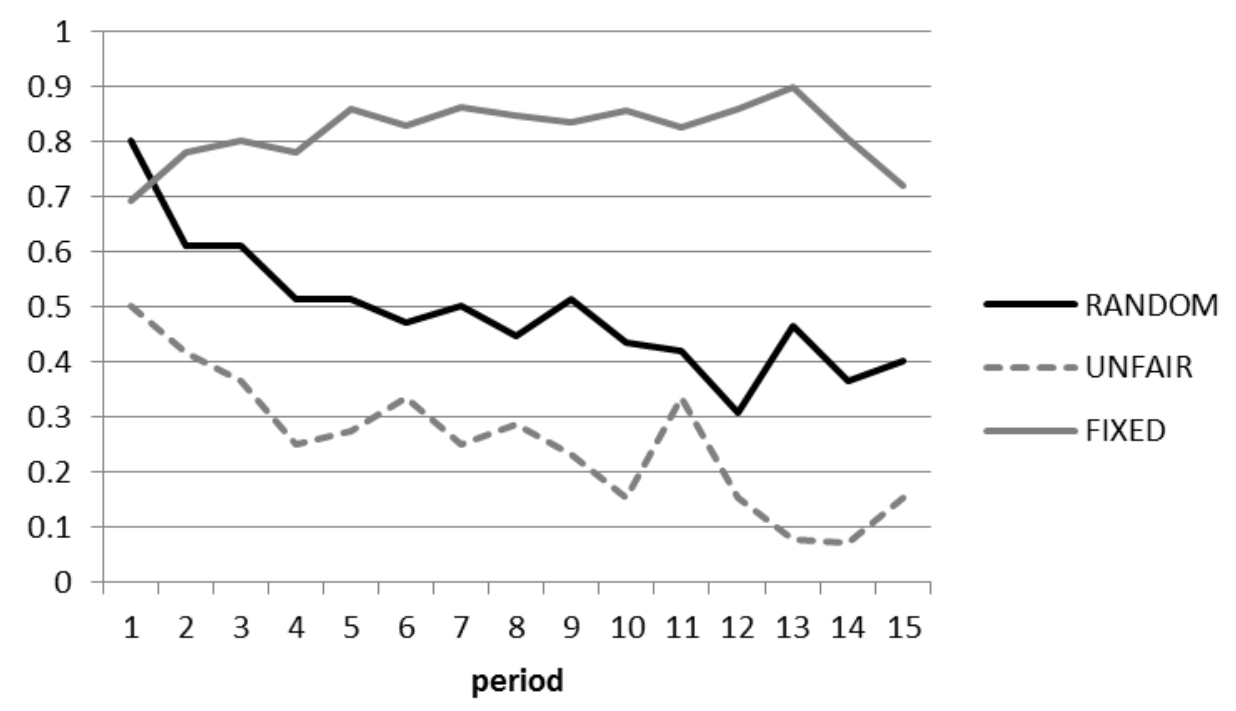

FIGURE 3.-Share of concluded employment contracts across treatments

\begin{abstract}
Result 3 (Persistence of employment contracts): About 50 percent of all concluded contracts are employment contracts in treatment RANDOM. The share of employment contracts declines from its initial value of 80 percent, but then levels out at about 40 percent.
\end{abstract}

Why do we observe so many more employment contracts in treatment RANDOM than the self-interest model predicts? We conducted treatment UNFAIR to address this question; it differs from treatment RANDOM only in that we exogenously manipulated the share of task 3 assignments in employment contracts: principals can only decide about the task assignment with a probability of 0.2 , while task 3 is imposed automatically with a probability of 0.8 . Figure 3 shows that employment contracts vanish over time in treatment UNFAIR. The difference in the share of employment contracts between treatment RANDOM and UNFAIR is statistically significant (rank-sum test on matching group differences, $\mathrm{p}=0.096$ ). ${ }^{14}$ This shows that the fair behavior of many principals is a causal determinant for the persistence of employment contracts in one-shot interaction, which is summarized in the following result

\footnotetext{
${ }^{14}$ Recall that we only have two matching groups in treatment UNFAIR which may explain why the significance level is just below 10 percent. We can justify the application of a one-sided p-value (in which case $p=0.048$ ), however, because we have a directed hypothesis for the comparison between RANDOM and UNFAIR.
} 


\begin{abstract}
Result 4 (Fair behavior of principals explains the persistence of employment contracts): Task 3 is imposed in about 90 percent of the employment contracts in treatment UNFAIR, while task 3 is implemented in only 50 percent of the cases in treatment RANDOM. As a result, employment contracts vanish in treatment UNFAIR, but persist in treatment RANDOM.
\end{abstract}

\title{
5.2 Authority and the Limits of Power in Relational Contracts
}

Principals and agents in treatment RANDOM are restricted to one-shot interactions. This case is certainly important in practice, but there are also many situations in which it is more plausible to assume that principals and agents can interact repeatedly if they wish to do so, and that they can condition their decisions on past experiences. The principals' and agents' IDs are fixed in treatment FIXED and observable for the duration of the experiment. This enables principals and agents to form long-term relations. How does this affect the prevalence of sales and employment contracts? Our next result provides an answer.

\footnotetext{
Result 5 (Dominance of employment contracts with fixed IDs): The large majority of contracts in treatment FIXED are employment contracts and except for the end game effect - the prevalence of employment contracts even increases over time.
}

This result thus rejects Hypothesis 1 (pure self-interest), while it is again consistent with Hypothesis 2 (social preferences). Figure 3 provides evidence for Result 5. The figure shows that the share of employment contracts in treatment FIXED is very stable at a level between 80 and 90 percent, with a slight drop to about 70 percent in the last two periods. The difference in the share of employment contracts between FIXED and RANDOM is significant (rank-sum test on matching group differences, $\mathrm{p}=0.016$ ).

Why do we observe so many more employment contracts in treatment FIXED than in treatment RANDOM? This question is addressed in our next result.

Result 6 (Power abuse and payoffs in relational contracts): Principals in treatment FIXED abuse their power significantly less often than in treatment RANDOM and in treatment UNFAIR. Both principals and agents earn significantly higher payoffs with employment contracts than with sales contracts. 
Figures 4 and 5 provide evidence for Result 6 . Figure 4 displays the share of principals who abuse their power and the share of employment contracts in treatments FIXED, RANDOM, and UNFAIR. It shows that there is a strong negative association between the incidences of power abuse $(0.21,0.51$, and 0.93 percent, respectively) and the share of employment contracts $(0.82,0.49$, and 0.25 , respectively). The difference in the frequency of power abuse between treatments FIXED and RANDOM and between RANDOM and UNFAIR is statistically significant (rank-sum test on matching group differences, $\mathrm{p}=0.007$ and $\mathrm{p}=0.046$, respectively.

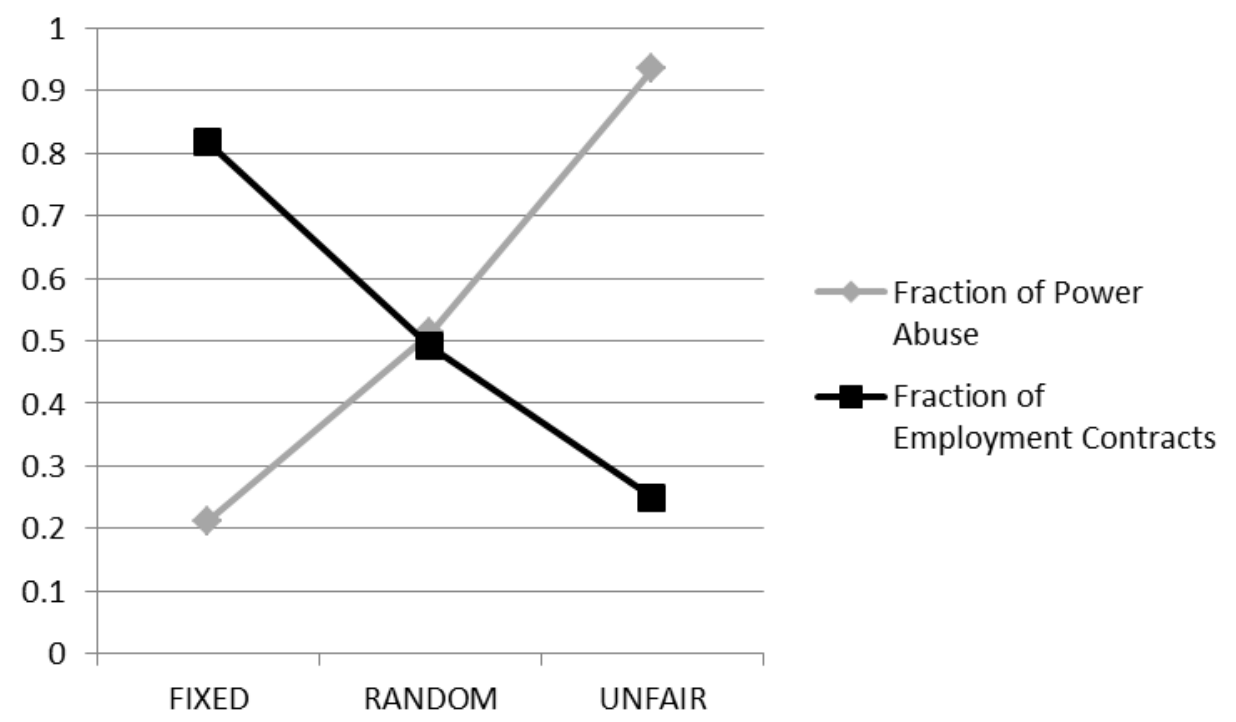

FIGURE 4.-Frequency of power abuses and the share of employment contracts.

Figure 5 shows that both principals and agents are better off under employment contracts in a given period. Principals realize average profits of 81.2 under employment contracts and 44.5 under sales contracts, and agents realize an average income of 59.4 under employment contracts and 50.7 under sales contracts. The difference is highly significant for principals and marginally significant for agents (rank-sum tests on matching group averages, $\mathrm{p}=0.004$ and $\mathrm{p}=0.078$, respectively). The conflict of interest with regard to contract type thus disappears with fixed IDs, and both principals and agents prefer employment contracts over sales contracts. 


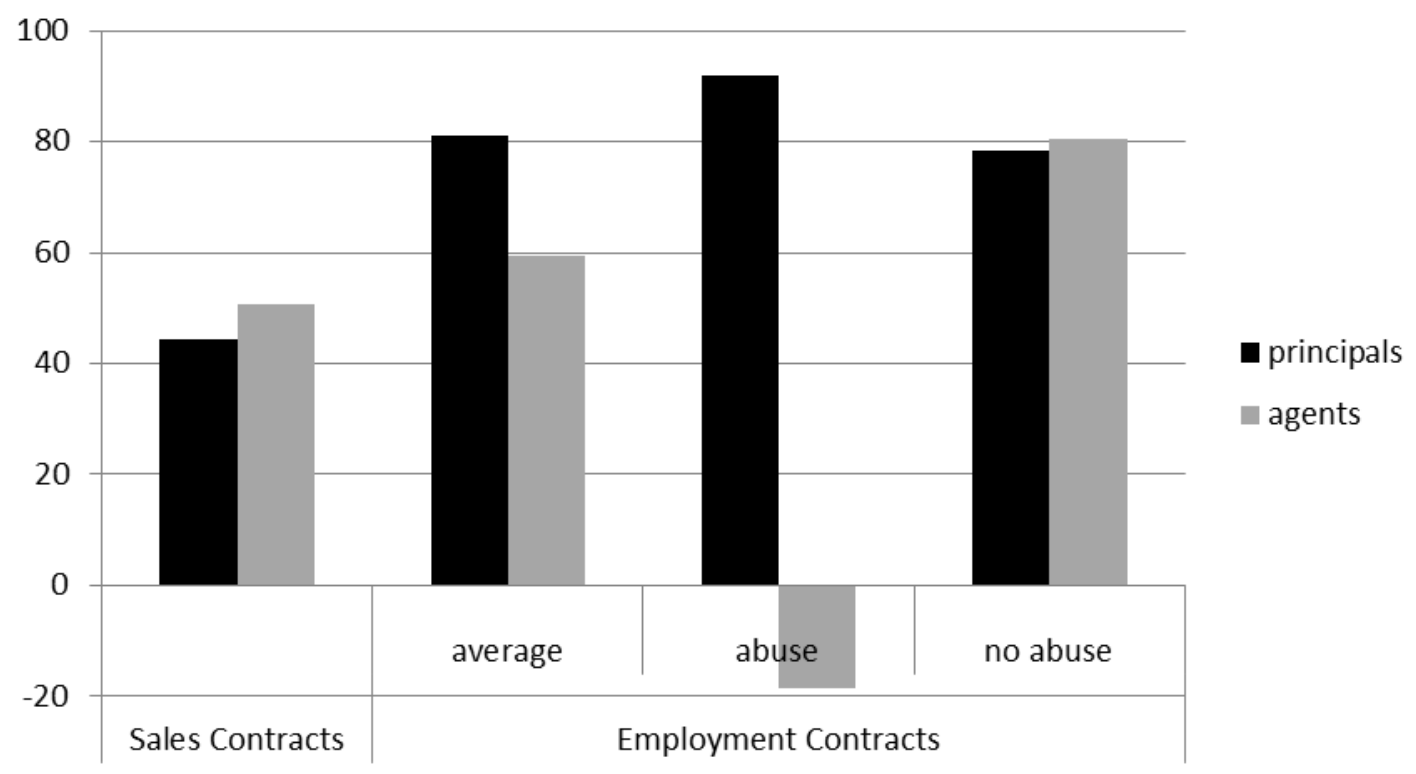

FIGURE 5.--Per period averages of principals’ profits and agents' incomes in concluded contracts in treatment FIXED.

Figure 5 also shows that, as in treatment RANDOM, even the principals who do not abuse their power make higher profits under employment contracts (78.3) than they earn on average under sales contracts, and that the principals who abuse their power make higher profits (91.9) than the fair principals. Both differences are highly significant (rank-sum tests on matching group averages, $\mathrm{p}=0.004$ in both tests). Agents who are exploited again make substantial losses on average (-18.6), but there are far fewer of these cases.

Why do principals abuse their power much less often with fixed IDs than with random IDs, even though they could increase their profits in the current period by doing so? The answer to this question is given by the following result.

\section{Result 7 (Power abuse, termination of relationships, and future profits): If a principal abuses his power in treatment FIXED, the authority relationship with his agent almost always breaks up. The principal's future profits are reduced significantly in this case.}

We only observed one single case where a principal abused his power in an employment contract, made a repeat employment contract offer to the same agent, who then accepted the offer. Thus, the abuse of power in an employment contract almost certainly terminates the authority relationship, which is costly to the principal. Panel A of Figure 6 shows a 
principal's average future profit in treatment FIXED depending on whether he abused his power under the current employment contract or not. The figure considers all observations where a principal had an accepted employment contract in a given period and calculates the profits in all future periods (not accounting for the current period) separately for principals who abused their power in the current period and those who did not. The figure shows that principals who do not abuse their power under an employment contract realize higher future profits throughout the experiment. Future profits naturally decline in later periods, as does the difference between abuse and no abuse. The differences shown in the figure are, however, highly significant in all three period bins (rank-sum tests on matching group averages, $\mathrm{p}=0.004$ in all three tests). Note that the short term monetary benefit of power abuse is always 30 , but the average cost in terms of future profit losses is significantly larger in all three period bins. This even holds for every single period except for the very last one in the final bin with periods 11 to 14 . It is thus in the principals' long term interest to treat their employees well and to refrain from imposing task 3.

Panel A

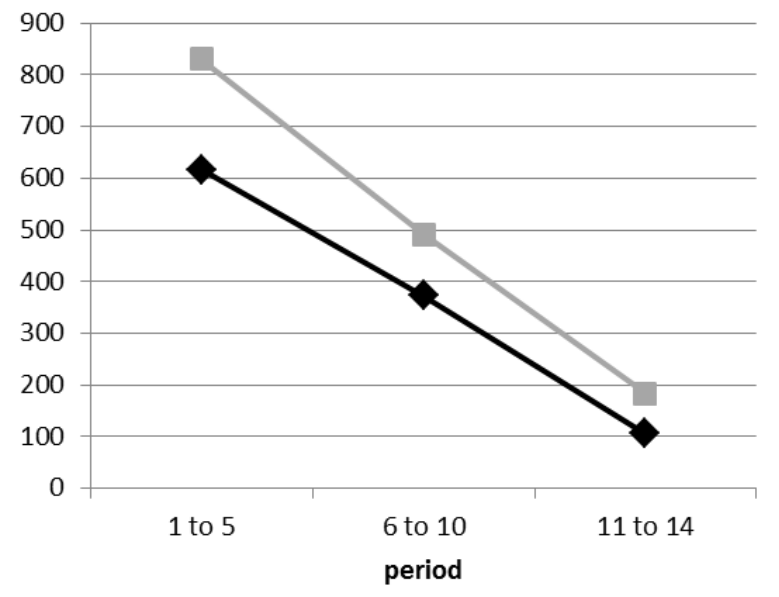

Panel B

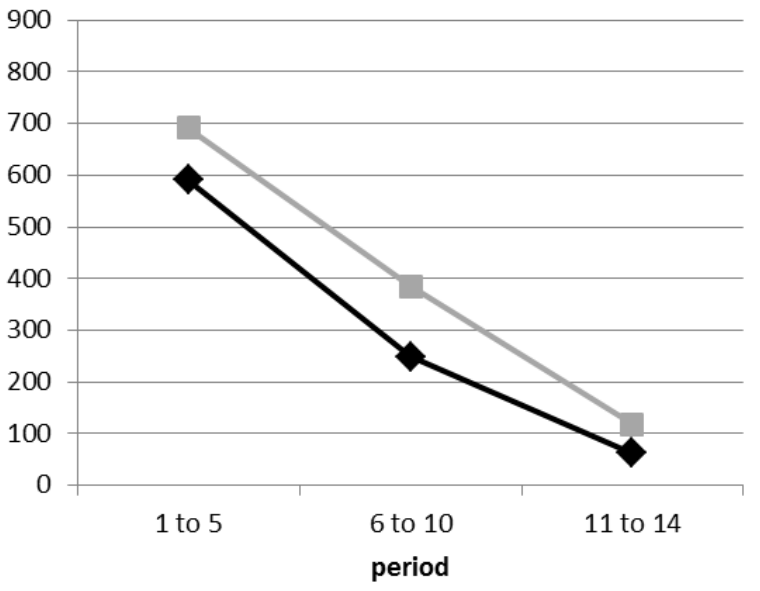

-abuse no abuse

FIGURE 6.-Principals' future profits (Panel A) and agents' future incomes (Panel B) in treatment FIXED depending on the principal's choice whether or not to abuse his power.

As an aside, it is interesting to observe that an agent's future income is also reduced if his principal exploits him in a given period. Agents thus earn a rent in viable long-run employment relations. This can be seen in Panel B of Figure 6, showing an agent's average future income depending on whether his principal abused his power under an employment contract or not. The figure considers all observations where an agent accepted an 
employment contract in a given period and then calculates the incomes in all future periods (not taking the current period into account) separately for agents who were exploited and those who were not. It is clear that agents who were not exploited realize higher future incomes throughout the experiment. Future incomes naturally decline in later periods, and so does the difference between power abuse and no power abuse. The differences shown in the figure are, however, (highly) significant in the latter two period bins (rank-sum tests on matching group averages, $\mathrm{p}=0.010$ and $\mathrm{p}=0.013)$, but not in periods 1 to $5(\mathrm{p}=0.873) .^{15}$

Employment contracts are typically part of a long term relation between the employer and the employee, while sales relationships are often more short term. It is therefore interesting to ask whether our framework also enables us to explain these patterns. Note that there is no moral hazard problem associated with a sales contract in our set up because all the terms of trades are settled ex ante and enforceable for third parties ex-post. There is therefore no reason to enter a long term relation under sales contracts and we should observe that sales contracts do not establish long term relations. In the case of employment contracts, however, Hypothesis 2 and Result 7 suggest that the principals can be disciplined through the agents' threat of dissolving the relationship after a power abuse. In other words, there are equilibria in treatment FIXED in which the principal benefits from treating the agent fairly and trading repeatedly with the same agent. This implies that employment contracts should be associated with long-term relationships. The next result shows that our data indeed meet these predictions.

\section{Result 8 (Contract type and length of trading relationships): No long-term relationships emerge under sales contracts in treatment FIXED, meaning that trades are predominantly one-shot. In contrast, most employment contracts are written in long-term relationships that significantly reduce the problem of power abuse.}

Figure 7 provides evidence for Result 8 . The figure shows that almost three quarters of all the transactions under sales contracts take place in one-shot interactions. In contrast, less than one-third of all transactions under employment contracts take place in one-shot interactions, and over 40 percent take place in relationships that last five or more periods.

\footnotetext{
${ }^{15}$ Note that we have very few observations of principals who abuse their power in several of the six matching groups in the first period bin (periods 1 to 5); the numbers of observations in the six matching groups are 1, 1, 2, 3,5 , and 8 , respectively.
} 


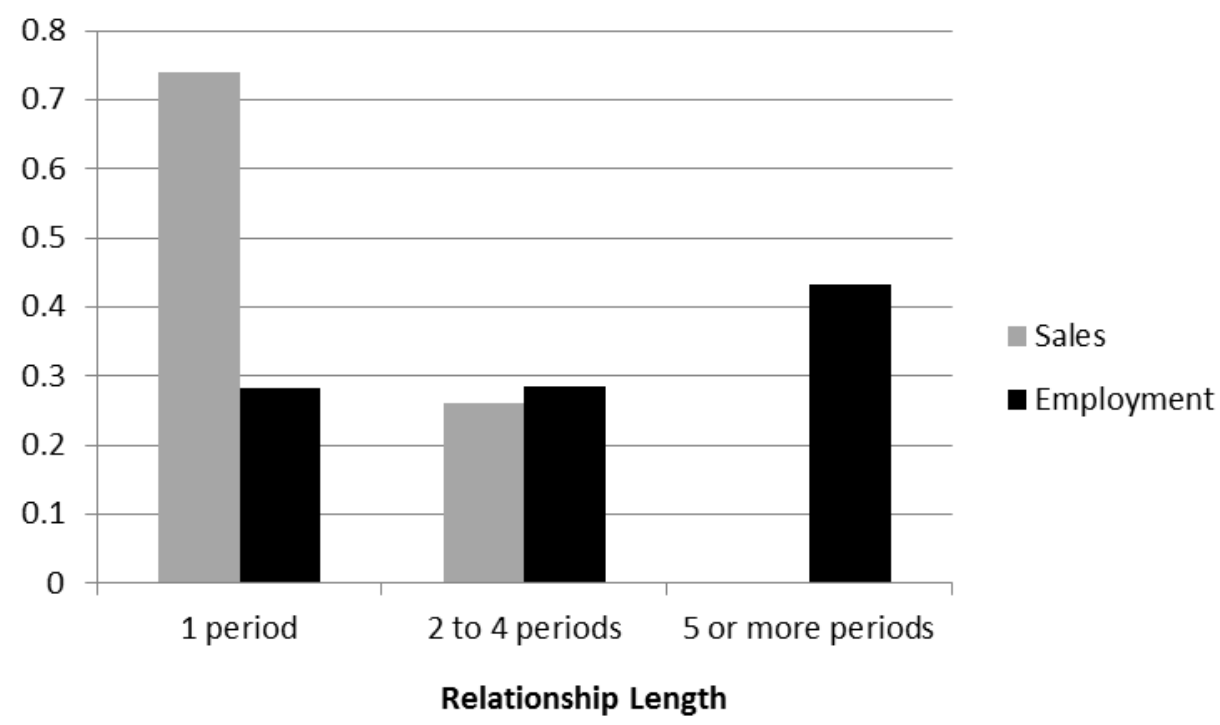

FIGURE 7.--Percentage of transactions in long-term relations.

The reason for the high share of transactions in long-term employment relationships is the significant reduction of the problem of power abuse. While the frequency of unfair task assignments in relationships that lasted for one period closely matches the level of 50 percent observed in treatment RANDOM, the level drops to 22 percent in relationships of length 2 to 4 , and we observe almost no power abuse (1 percent) in relationships that lasted for 5 or more periods.

\subsection{Transaction Costs of Sales and Employment Contracts}

What are the implications of our experimental findings for the efficiency of sales and employment contracts, i.e., for the transaction costs the two different modes of governance cause? The next result provides the answer for concluded contracts.

Result 9 (Efficiency of concluded employment and sales contracts): In treatment RANDOM, concluded employment contracts are more efficient on average than concluded sales contracts because half of the principals do not abuse their power and choose the efficient task, but the difference is not significant. The efficiency advantage of concluded employment contracts over concluded sales contracts is larger and highly significant in treatment FIXED. 


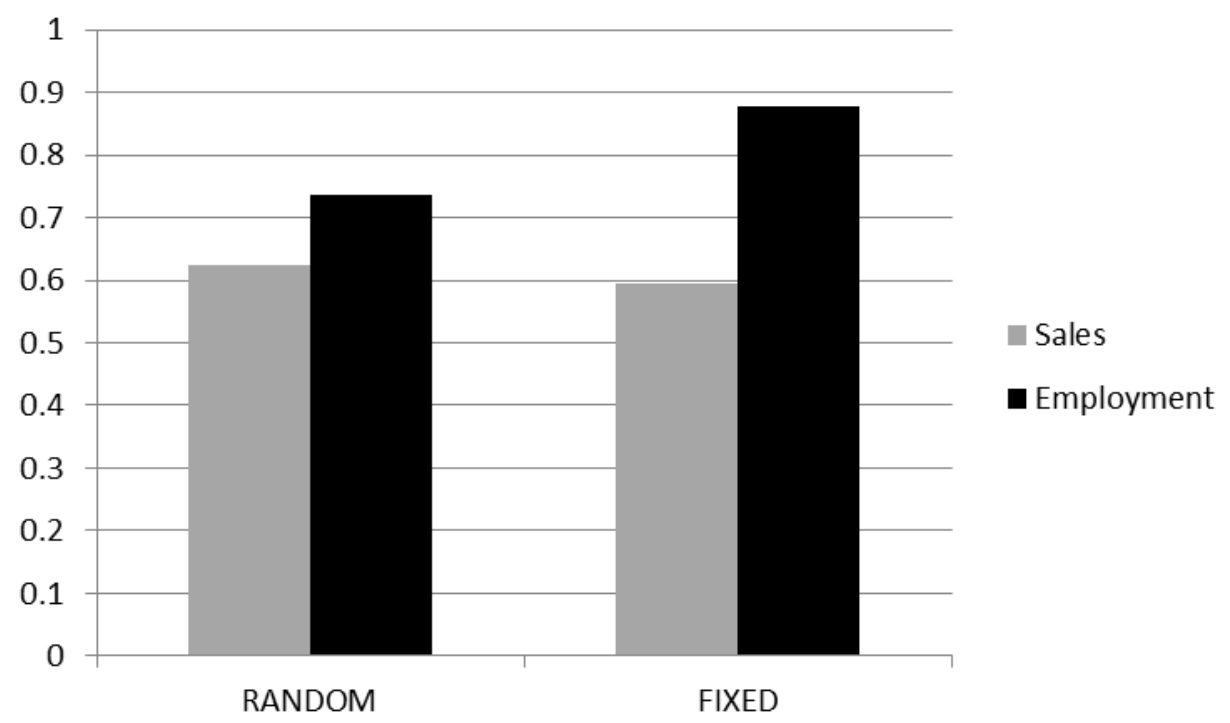

FIGURE 8.- Share of maximum surplus achieved in concluded employment and sales contracts in treatments RANDOM and FIXED.

Figure 8 provides evidence for Result 9. The maximum surplus of 160 is achieved if the agent chooses task 1 in state 1 and task 2 in state 2 . A sales contract is inefficient because it always assigns the same task, independent of the state of the world. An employment contract is inefficient if the principal abuses his power and forces the agent to execute task 3 . The employment contract is more efficient (73.7 percent of the maximum surplus) than the sales contract (62.5 percent) in treatment RANDOM, but the difference is not significant (ranksum test on matching group differences, $\mathrm{p}=0.109$ ). The efficiency of concluded employment contracts is much larger than that of concluded sales contracts in treatment FIXED (87.9 percent versus 59.5 percent; rank-sum test on matching group differences, $\mathrm{p}=0.004$ ). Comparing treatments, we find that the employment contract exhausts the potentially available surplus to a higher degree in treatment FIXED, while there are no treatment differences under sales contracts (rank-sum tests on matching group differences, $\mathrm{p}=0.007$ and $\mathrm{p}=0.522$, respectively).

Up until now, we have only considered concluded contracts. There is, however, a second source of transaction costs. If an agent does not accept a contract offer, there is no trade, and the surplus is lost. In treatments RANDOM and FIXED, 131 and 114 out of 720 possible trading opportunities, respectively, were not realized. ${ }^{16}$ Among these missed opportunities, the vast majority were rejected employment contract offers (87.8 and 88.6 percent in treatments RANDOM and FIXED, respectively). Result 2 in treatment RANDOM

\footnotetext{
${ }^{16}$ We have 16 principals and 16 agents per session. A session lasts for 15 periods. We have 3 sessions for each treatment, which results in $16 \cdot 15 \cdot 3=720$ trading opportunities.
} 
showed clearly that there is a strong conflict of interest between principals and agents about which type of contract to conclude, while both parties prefer the employment contract in treatment FIXED (Result 6). This explains why the rejection rate for employment contracts is 28.5 percent in treatment RANDOM, while it is only 5.1 percent for sales contracts. ${ }^{17}$ The rejection rate for employment contracts in treatment FIXED is 16.9 percent, which is significantly lower than in treatment RANDOM (rank-sum test on matching group differences, $\mathrm{p}=0.055)$. The rejection rate for sales contracts is 10.5 percent, which is not significantly different from treatment RANDOM (rank-sum test on matching group differences, $\mathrm{p}=0.378$ ). Our next result compares the total transaction costs of sales and employment contracts taking all sources of inefficiencies - power abuse in employment contracts, contract rejections, and inefficient task assignment in sales contracts - into account.

\section{Result 10 (Transaction costs of sales and employment contracts): There is no significant difference in total transaction costs between sales and employment contracts in treatment RANDOM, while the total transaction costs are significantly lower under employment contracts in treatment FIXED.}

Figure 9 provides evidence for Result 10. The figure shows the total transaction cost incurred in the different contracting modes across treatments. We display these transaction costs as a share of the maximum available surplus, i.e. we show how much of this surplus is wasted by incurring transaction cost. The difference between employment contracts (47.3 percent) and sales contracts (40.6 percent) is not significant in treatment RANDOM (rank-sum test on matching group averages, $\mathrm{p}=0.109$ ). This finding is consistent with the observation that both contracting modes in treatment RANDOM govern a substantial share of the transactions. The transaction costs are substantially lower under the employment contract (27.0 percent) than under the sales contract (46.8 percent) in treatment FIXED - a difference that is highly significant (rank-sum test on matching group averages, $\mathrm{p}=0.007$ ). This is consistent with the

\footnotetext{
${ }^{17}$ These rejection rates are computed as follows. We have 300 accepted sales contracts in treatment RANDOM, for example, and 16 of the untaken contract offers at the end of the public contracting phase were sales contract offers. The rejection rate is then calculated as $16 /(300+16)=0.05$. We did not calculate the rejection rate simply as rejected sales contract offers divided by total number of sales contract offers because each principal made one private offer and one public offer, only one of which could be accepted by design. The rejection rate as calculated above does not account for rejections in the private contracting phase, because a single agent might get several offers of which he can accept only one by design. By considering the total number of accepted contracts, it does, however, account for both privately and publicly offered contracts because it is irrelevant whether accepted contracts were concluded in the private or in the public contracting phase.
} 
observation that employment contracts govern the large majority of transactions in treatment FIXED. Comparing contract types across treatments, there is no difference in total transaction costs of sales contracts, but the total transaction costs of employment contracts are significantly lower in treatment FIXED (rank-sum tests on matching group averages, $\mathrm{p}=0.262$ and $\mathrm{p}=0.025$, respectively).

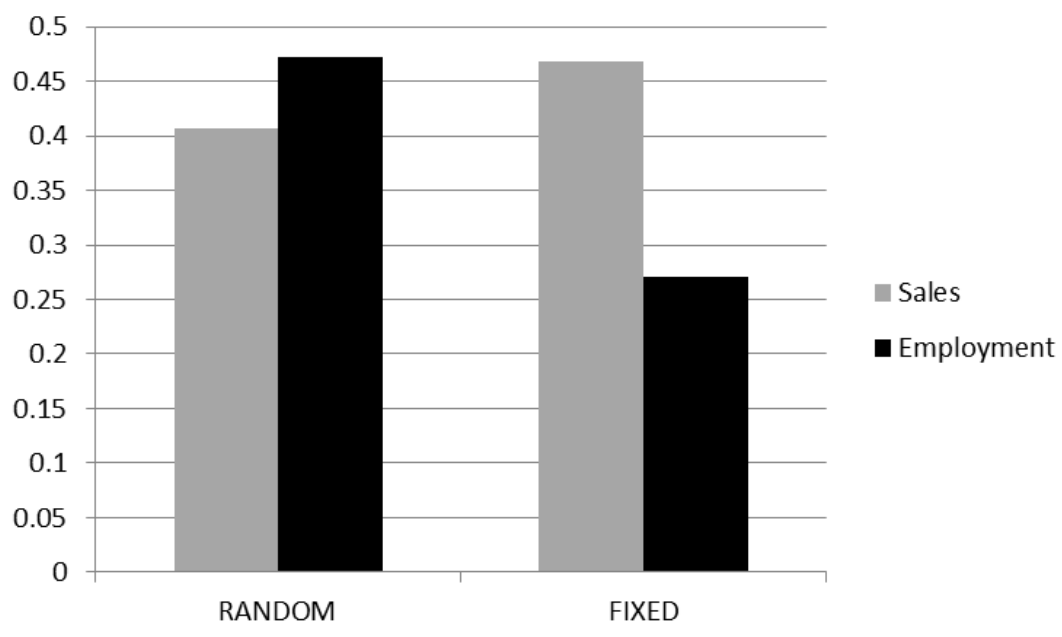

FIGURE 9.- Transaction costs of sales and employment contracts as share of the maximum available surplus.

Note that all (short- and long term) employment contracts in treatment FIXED are taken into account in Result 10. However, we have seen that employment contracts that were concluded in long-term relationships have much lower frequencies of power abuse and also a much higher chance of renewal, i.e., acceptance. Total transaction costs for these contracts are thus even lower. Our experiments show that these long-term relationships arise endogenously with fixed IDs as a result of their solution of the employer moral hazard problem and the associated reduction in the total transactions costs of employment contracts.

\section{Implications for the Theory of the Firm}

Coase famously described the firm as a system in which power and subordination prevail in his 1937 paper: "If a workman moves from department $Y$ to department $X$, he does not go because of a change in relative prices, but because he is ordered to do so (p. 387). [...] It is important to note the character of the contract into which a factor enters that is employed within a firm. The contract is one whereby the factor [...] agrees to obey the directions within 
certain limits. The essence of the contract is that it should only state the limits of the power of the entrepreneur. Within these limits, he can therefore direct the other factors of production (p. 391).”

Alchian and Demsetz (1972, p. 777) radically question this view of the firm: "It is common to see the firm characterized by the power to settle issues by fiat, by authority, or by disciplinary action superior to that available in the conventional market. This is delusion. [...] [The firm] has no power of fiat, no authority, no disciplinary action any different in the slightest degree from ordinary market contracting between any two people. [...] What then is the content of the presumed power to manage and assign workers to various tasks? Exactly the same as one little consumer's power to manage and assign his grocer to various tasks."

Instead replacing the price mechanism with a system of power and subordination, Alchian and Demsetz describe the key characteristic of firms as the team use of inputs and the centralized position of some party in the contractual arrangement of all inputs. Although we do not set up a team production environment, the results of our paper also have some bearing on this "debate” between Alchian and Demsetz (1972) and the Coasian view of the firm (Coase 1937, Simon 1951).

We do not dispute the potentially important role of team production and a centralized monitor in the firm. Alchian and Demsetz' claim that the firm has no authority any different from the little consumer's power to assign his grocer to various tasks is questionable in our view, however, for the following reasons. The employer is generally legally allowed to give orders to the worker that must be obeyed, while the grocer does not sign a contract that obliges him to obey the little consumer's task assignments. In other words, the relation between the consumer and the grocer is based on a sales contract - a specific product with well-defined properties is exchanged for a well-defined price - while the relation between an employer and a worker is based on an employment contract that confers the right of task assignment to the employer. Therefore, the grocer does not face any moral hazard problem because the little consumer cannot impose an abusive task on him, while the agent in the employment contract faces this exact risk. In the same way that the agent in our sales contract faced no risk of power abuse, the grocer does not face that risk because in sales contracts the terms of trade are completely settled in the market.

The terms of trade are not fully described in the employment contract, however, because the employer has the right to determine the tasks ex-post. Due to the non-verifiability of the states of the world, legal rules and third party enforcement cannot solve the resulting moral hazard problem; this must be done by disciplining the employer in repeated exchanges. 
This has important consequences for the functioning of the market. In a perfectly competitive market with third party enforcement of well-defined terms of trade, the trading parties are on the margin indifferent between trading with their current partner or with a different partner so that the "firing" of a trading partner imposes no cost. Trading with partner $\mathrm{X}$ is as good as trading with partner Y. Trading relationships are therefore typically one-shot, as they are in our experiments with regard to sales contracts.

In contrast, theoretical contributions (MacLeod and Malcomson 1989, 1998) and the evidence in this paper as well as in others (Brown, Falk and Fehr 2004, 2012) suggest that the endogenous enforcement of contracts in the presence of moral hazard problems is associated with the pervasive existence of rents. The break-up of an employment relationship is therefore generally associated with considerable costs for both parties, meaning that both parties have a strong interest in continuing the relationship. This explains why employment contracts are turned into long-lasting employment relations, while the trading parties are indifferent to continued relationships in sales contracts. ${ }^{18}$

Taken together, very different forces govern the relationship between the little consumer and the grocer, and this relationship is of a very different nature than that between an employer and a worker. The grocer faces no risk of abusive task assignments and there is thus no need to discipline the consumer by leaving a rent to him. In contrast, the agent who enters an employment contract faces such a risk, and the employer and the agent must earn a rent from the continued relationship to prevent opportunistic behavior.

Our paper also provides a framework that enables us to identify the conditions under which "Marxian" features characterize the firm (Marglin 1974, 1975). The firm is characterized as a hierarchical system under both the Marxian and the Coasian view where the employer has the power to direct the allocation of resources within the firm. However, while the firm's power and hierarchy is a tool for the exploitation of workers in the Marxian view, these tools are used to achieve an efficient allocation of resources within the firm in the Coasian view. In fact, fiat based on power is an allocation mechanism in the Coasian view that is often more efficient than the price mechanism, which is the very reason why firms exist.

Our results confirm the Coasian view that the transaction costs associated with an employment contract as compared to those of a sales contract are a causal factor for the

\footnotetext{
${ }^{18}$ There may, of course, be other factors such geographical proximity that facilitate repeated buying at the same grocer. But this still does not turn sales contracts that are typically executed on the spot into employment contracts with legal rights for task assignment.
} 
emergence and viability of employment contracts (i.e., firms). In this sense, firms exist because they give rise to lower transaction costs. We also show, however, that the Marxian idea that power can be used for exploitation is real. Many employees will be abused under some conditions, when employers cannot commit to treating their employees fairly. Under these circumstances, employment contracts (firms) are used as a tool for exploitation. Ironically, this tool only works in treatment RANDOM because of the existence of fairminded subjects in the role of the principal. Without these fair-minded employers, workers do not accept employment contracts (as shown in treatment UNFAIR).

It is also important to point out in this context that there is no guarantee that this problem will always be solved, even in treatment FIXED, where our subjects largely solved the moral hazard problem. Multiple equilibria exist in repeated interaction, and the purely selfish employers always abuse their workers under employment contracts in some of these equilibria. Workers then resist accepting these contracts, similar to what we observed in treatment RANDOM. In other words, reputational mechanisms may not always be sufficient to solve the principals' moral hazard problem. ${ }^{19}$

This points to the potentially important role of labor unions and labor laws restricting the firms' exploitative capacities - even in environments where reputation building is possible - by strengthening workers' rights, which might prevent a bad equilibrium. If complete state-contingent labor contracts could be written, constraints on the employers' action space would only reduce efficiency. In an incomplete contracts environment, however, where employers face the temptation to assign abusive tasks to their workers, labor unions and labor laws can be efficiency enhancing because they may enable the employer to credibly commit to not abuse his workers. This account of labor unions and labor laws echoes the contributions of Freeman and Medoff $(1979,1984)$ who argued that unions may not just represent monopolies (which they do), but that they also may enhance efficiency by helping improve working conditions and reducing labor turnover, for example. Our set-up provides a framework in which this role of labor laws and labor unions can be discussed. Our results

\footnotetext{
${ }^{19}$ It is tempting to relate the resistance against employment contracts in treatment RANDOM to the historical evidence on workers' strong distaste to factory work during the early phase of the industrial revolution (see, e.g., Pollard 1963). Factory work during this time was characterized by employers' nearly unconstrained rights to determine working conditions, fines, and other disciplinary measures (such as corporal punishment). Thus, "the very recruitment to the uncongenial work was difficult, and it was made worse by the deliberate or accidental modelling of many works on workhouses and prisons, a fact well known to the working population" (Pollard 1963, p. 254).
} 
suggest, for example, that regulations that help employers solve their commitment problem will also reduce labor turnover and the costly break-up of employment relations. ${ }^{20}$

Finally, our paper is related to recent contributions to the human resource management literature on high-performance work systems (HPWS). HPWS are a departure from Taylorist forms of labor relations. Under Taylorism, employers severely constrain the workers' action space and impose tight controls on them, while employers under HPWS partially delegate decision rights to workers, enabling them to act on their private information and ingenuity as they see fit in order to solve the problems that arise on the job. ${ }^{21}$ HPWS can thus potentially increase productivity. HPWS greatly reduce the employers' scope for exploitative task assignments by granting employees the right to assign themselves to tasks within certain limits. However, HPWS make the employer vulnerable because it remains at the worker's discretion to use his flexibility to benefit the employer or to shirk. We show experimentally in Bartling, Fehr, and Schmidt (2012) that the employers' opportunities to screen for work attitudes and labor market competition are causal factors for the viability of HPWS. In our current paper, we analyze the conditions under which employment contracts that give the employer authority over his workers are viable. ${ }^{22}$ In both cases, the general theme is the identification of the conditions that enable the efficient use of decision rights in trade relationships plagued with incomplete contracting problems.

\section{Conclusions}

In this paper, we propose a novel experimental design to address an old question in the theory of the firm: Under what conditions is a transaction more efficiently carried out in a firm than in a market? We identify the conditions in our experiments under which employment contracts (vertical integration) outperform sales contracts (non-integration). An employment contract allows the principal to quickly adjust the task the agent must execute to new information such as short-term changes in demand, but it also gives rise to an employer moral

\footnotetext{
${ }^{20}$ Note that our framework can also help assess the efficiency costs of constraints on the employers' rights to assign employees to tasks. If a task is abusive in some states of the world but very efficient in other states of the world, regulations that rule out these tasks altogether impose efficiency costs because assignment of the task is desirable in some states. Thus, if reputation solves the employers' moral hazard problem, we should not rule out this task. However, if labor relations are in a bad equilibrium, constraining the employers' right to impose these tasks may be second-best efficient.

${ }^{21}$ See, for example, Ichniowski and Shaw (2003) for an overview of these work practices.

${ }^{22}$ Note that within the framework of our current experimental design, the introduction of a HPWS could be interpreted as the employer's promise to bind his hands and let the worker determine the task after the realization of the state of the world. The worker could then use his power to choose the efficient task or the task that minimizes his cost. In our current paper, we focus on the worker's risk that the employer will not keep his promise and order the worker to choose the inefficient task.
} 
hazard problem because the principal has the power to exploit his agent by forcing him to execute a profitable but expensive and thus inefficient task. A sales contract solves the employer moral hazard problem by fixing the task to be executed in advance, but this task might turn out to be inefficient ex-post. We find that the principals have an almost universal preference for employment contracts - regardless of whether they are used in an efficient or an inefficient way - while workers resist accepting employment contracts if a large number of principals use them to assign inefficient (abusive) tasks. Fair principals prefer the employment contract because it enables them to reap efficiency gains which they are willing to share with their agents. Selfish principals prefer the employment contract because it either allows them to make a profit at the cost of their workers or, if they can build a credible reputation for non-abusive task assignment, they can reap the efficiency gains of this contract. We show that if both the principals' fairness and reputation can play a role, the majority of trades take place under employment contracts that are embedded in long-run relations between the trading parties.

Our results inform the theory of the firm by showing how behavioral forces shape an important transaction cost of integration - the abuse of authority - and by providing an empirical basis for assessing differences between the Marxian and the Coasian view of the firm, as well as Alchian and Demsetz's (1972) critique of the Coasian approach. In addition, our experimental set up provides a framework where constraints on principals' authority either through labor laws or through labor unions - are not automatically efficiency reducing because they may enable principals to better commit themselves to an efficient use of their authority.

This perspective on constraints on the principals' authority also raises interesting questions for future research. For example, tasks that impose high costs on the agents may be nevertheless efficient in some states of the world but inefficient in others (e.g. because of variations in revenue across states). Therefore, completely ruling out such tasks is inefficient, unless the principals are unable to credibly commit to an efficient task assignment. However, if the trading parties are generally in a bad reputational equilibrium where agents strongly believe that the principals abuse authority to their own advantage, some legal constraints on the principals' authority may improve efficiency. Alternatively, it may be possible to improve the principals' incentives to acquire a good reputation by, for example, by creating an institution that provides public information about the principals' reputation.

Another interesting question is the extent to which the principals' ability to commit to an efficient use of authority depends on labor market conditions and imperfections. It may, 
for example, be more difficult for the principals to commit in case of an excess supply of labor because they can easily find a replacement for a quitting worker. Or in case of asymmetric information about the state of the world, the agents may believe that a task assignment with high costs is the result of inefficient abuse, while in fact it was efficient. These circumstances may make the development of cooperative employment relations considerably more difficult, but they also provide interesting challenges for future research.

\section{References}

Alchian, Armen, and Harold Demsetz. 1972. "Production, Information Costs, and Economic Organization.” American Economic Review, 62 (5): 777-795.

Battigalli, Pierpaolo, and Martin Dufwenberg. 2007. "Guilt in Games." American Economic Review, Papers \& Proceedings, 97(2): 170-76.

Bartling, Björn, Ernst Fehr, and Klaus M. Schmidt. 2012. "Screening, Competition, and Job Design: Economic Origins of Good Jobs,” American Economic Review, 2012, 102(2), 834-864.

Bartling, Björn, and Klaus M. Schmidt. 2012. "Reference Points in Renegotiations: The Role of Contracts and Competition," Working Paper No. 89, Department of Economics, University of Zurich.

Bolton, Gary E., and Axel Ockenfels. 2000. "ERC - A Theory of Equity, Reciprocity and Competition.” American Economic Review, 90(1): 166-93.

Brown, Martin, Armin Falk, and Ernst Fehr. 2004. "Relational Contracts and the Nature of Market Interactions.” Econometrica, 72 (4): 747-780.

Brown, Martin, Armin Falk, and Ernst Fehr. 2012. "Competition and Relational Contracts

- The Role of Unemployment as a Disciplinary Device.” Journal of the European Economic Association. 10(4): 887-907.

Coase, Ronald. 1937. "The Nature of the Firm.” Econometrica, 4: 386-405.

Dufwenberg, Martin, and Georg Kirchsteiger. 2004. "A Theory of Sequential Reciprocity.” Games and Economic Behavior, 47(2): 268-98.

Falk, Armin, and Urs Fischbacher. 2006. “A Theory of Reciprocity.” Games and Economics Behavior, 54(2): 293-315.

Fehr, Ernst, Oliver Hart, and Christian Zehnder. 2011. "Contracts as Reference Points Experimental Evidence.” American Economic Review, 101(2): 493-525. 
Fehr, Ernst, Oliver Hart, and Christian Zehnder. 2012. "How Do Informal Agreements and Renegotiation Shape Contractual Reference Points?” Working Paper No. 43, Department of Economics, University of Zurich.

Fehr, Ernst, and Klaus M. Schmidt. 1999. “A Theory of Fairness, Competition, and Cooperation.” Quarterly Journal of Economics, 114(3): 817-68.

Fischbacher, Urs. 2007. “Z-Tree: Zurich Toolbox for Ready-Made Economic Experiments.” Experimental Economics, 10(2): 171-78.

Freeman, Richard B., and James L. Medoff. 1979. “The Two Faces of Unionism.” Public Interest, 57: 69-93.

Freeman, Richard B., and James L. Medoff. 1984. What Do Unions Do? New York: Basic Books.

Gibbons, Robert. 2010. “Transaction Cost Economics: Past, Present, and Future?” Scandinavian Journal of Economics, 112(2): 263-288.

Grosse, Stefan, Louis Putterman, and Bettina Rockenbach. 2011. "Monitoring in Teams: Using Laboratory Experiments to Study a Theory of the Firm," Journal of the European Economic Association, 9(4): 785-816.

Hart, Oliver and John Moore. 2008. “Contracts as Reference Points.” Quarterly Journal of Economics, 123(1):1-48.

Herweg, Fabian und Klaus M. Schmidt. 2012. "A Theory of Ex Post Inefficient Renegotiation,” SFB/TR 15 Discussion Paper No. 390.

Ichniowski, Casey, and Kathryn Shaw. 2003. "Beyond Incentive Pay: Insiders' Estimates of the Value of Complementary Human Resource Management Practices.” Journal of Economic Perspectives, 17(1): 155-80.

Kreps, David, Paul Milgrom, John Roberts, and Robert Wilson. 1982. "Rational Cooperation in the Finitely Repeated Prisoners' Dilemma.” Journal of Economic Theory, 27(2): 245-52.

MacLeod, W. Bentley, and James M. Malcomson. 1989. "Implicit Contract, Incentive Compatibility, and Involuntary Unemployment,” Econometrica, 57(2): 447 - 480.

MacLeod, W. Bentley, and James M. Malcomson. 1998. "Motivation and Markets," American Economic Review, 88(3): 388 - 402.

Marglin, Stephen Alan. 1974. "What Do Bosses Do?” Review of Radical Political Economics, 6 (2): 60-112. 
Marglin, Stephen Alan. 1975. "What Do Bosses Do? Part II” Review of Radical Political Economics, 7 (1): 20-37.

Masten, Scott E. 1984. “The Organization of Production: Evidence from the Aerospace Industry.” Journal of Law and Economics, 4: 403-417.

Monteverde, Kirk, and David J. Teece. 1982. "Supplier Switching Cost and Vertical Integration in the Automobile Industry.” Bell Journal of Economics, 13: 206-212.

Pollard, Sidney. 1963. "Factory Discipline in the Industrial Revolution.” The Economic History Review, 16(2): 254-271.

Rabin, Matthew. 1993. "Incorporating Fairness into Game Theory and Economics." American Economic Review, 83(5): 1281-302.

Simon, Herbert. 1951. “A Formal Theory of the Employment Relationship.” Econometrica, 19: 293-305. 